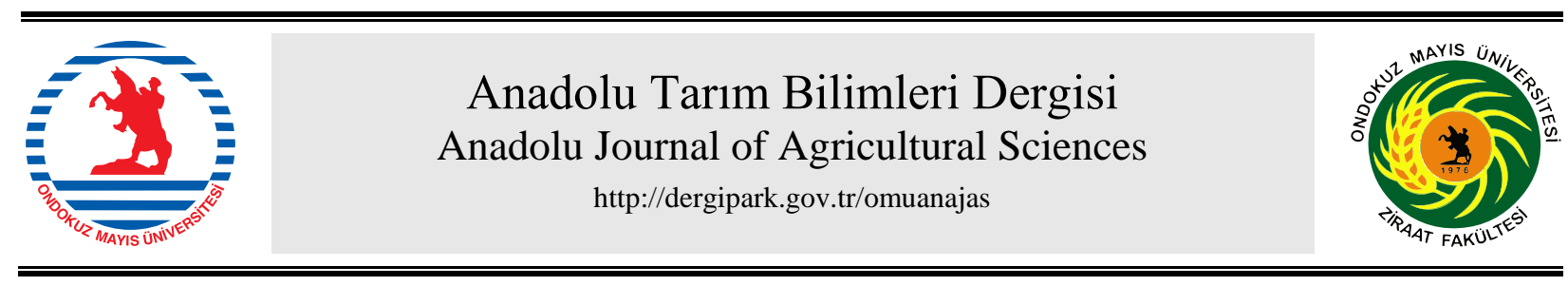

Araştırma/Research

Anadolu Tarım Bilim. Derg./Anadolu J Agr Sci, 34 (2019) ISSN: 1308-8750 (Print) 1308-8769 (Online) doi: $10.7161 /$ omuanajas. 463272

\title{
Pirina ve balık atıklarının birlikte kompostlanması ve toprak ıslahında kullanılması
}

\author{
Remzi İlay ${ }^{*}$, Gökhan Erarslan, Yasemin Kavdır \\ Çanakkale Onsekiz Mart Üniversitesi, Ziraat Fakültesi, Toprak Bilimi ve Bitki Besleme Bölümü, Çanakkale \\ *Sorumlu yazar / Corresponding author: rilay@comu.edu.tr
}

Geliş tarihi: 24.09.2018 Kabul tarihi 18.10.2018

\begin{abstract}
ÖZET
Gıda endüstrisinde üretim sonrasında açığa çıkan atıkların toprak düzenleyicisi olarak kullanılabilecek forma dönüştürülerek tarım alanlarında kullanılması, hem ekonomik hem de çevresel açıdan en iyi yöntemlerden biri olarak kabul edilmektedir. Ülkemizde faaliyet gösteren balık işleme fabrikalarında, balığın işlenmesi sonrasında önemli miktarlarda balık atığı (BA) ortaya çıkmaktadır. Ayrıca, zeytinyağı üretimi sonrasında da pirina (PA) olarak isimlendirilen katı atık açığa çıkmaktadır. Bu çalışmada balık atığı ve pirina kullanılarak yapılan kompostun (BPK) üç farklı dozunun (\% 3, \% 6, \% 9) kumlu tın bünyeye sahip toprağa uygulandıktan sonra, toprağın bazı fiziksel ve kimyasal özelliklerindeki değişimler belirlenmiştir. Bu amaçla kompost uygulanan topraklar 2.5 ay sabit sıcaklıktaki inkübatörde inkübasyona bırakılmıştır. İnkübasyon süresi sonunda BPK'nın toprak reaksiyonu $(\mathrm{pH})$, elektriksel iletkenlik (EC), toplam azot (TN), toplam karbon (TC) ve agregat stabilitesi (AS) gibi toprak özellikleri üzerine etkileri araştırılmıştır. BPK uygulamasıyla incelenen toprak parametrelerinde ve uygulanan dozlar arasındaki farkların istatistiki olarak önemli olduğu tespit edilmiştir $(\mathrm{p}<0.05)$. Artan BPK dozuyla $\mathrm{pH}$ ve $\mathrm{C} / \mathrm{N}$ oranı hariç diğer toprak parametre değerlerinin arttığı sonucuna ulaşılmıştır. En yüksek BPK uygulamasıyla pH' nın kontrole göre \% 5.9, C/N oranının ise $\% 45$ azaldığı görülmüsştür. \%9 BPK uygulaması sonrasında $\mathrm{EC}^{\prime}$ nin yaklaşı 14 kat, AS' nin \% 68, TN'nin \% 207, TC'nin \% 68 arttığı tespit edilmiştir.
\end{abstract}

Co-composting of olive pomace and fish wastes and use in soil improvement

\section{ABSTRACT}

The re-use of wastes produced from food industry in agriculture is considered to be one of the best methods both economically and environmentally. In Turkey, a significant amount of fish waste released in fish processing factories. Additionally olive oil production is also important in the region and solid waste that is remaining after olive oil production is called olive pomace (pirina). In this study, changes in some physical and chemical properties of sandy loam soil after applications of compost (FOC) with three different doses (3\%, $6 \%, 9$ $\%$ ) have been determined. For this purpose, the compost added soil was kept in incubator for 2.5 months. At the end of the incubation period, the effects of compost on soil $\mathrm{pH}$, electrical conductivity (EC), total nitrogen (TN), total carbon (TC) and aggregate stability (AS) were investigated. It was found that compost addition significantly changed measured soil parameters and doses were also statistically significant $(\mathrm{p}<0.05)$. It was determined that measured soil parameter values except $\mathrm{pH}$ and $\mathrm{C} / \mathrm{N}$ ratio increased with increasing compost doses. $\mathrm{pH}$ was decreased by $5.9 \%$ and $\mathrm{C} / \mathrm{N}$ was decreased by $45 \%$ compared to control with the highest compost application rate. It was found that EC was 14 times higher, AS was $68 \%$ higher, TN was $207 \%$ higher and TC was $68 \%$ higher in $9 \%$ FOC applied soils than those Keywords: Fish waste Olive pomace Compost Soil of control soil. 


\section{Giriş}

Artan nüfus ve buna bağlı olarak kentleşme hızının artması birçok çevresel soruna sebep olmaktadır. Çevresel sorunların başında ise atık yönetiminin yetersiz olması ve yerinde olmaması gelmektedir. Atıkların güvenli şekilde bertarafı veya geri dönüşümünün yetersiz bilgi, teknolojik ve ekonomik imkanlar dahilinde sınırlı kalması depolama sorunlarına ve çevre kirliliğine neden olabilmektedir. Global ölçekte toplam atık miktarının \%46'sını organik atıklar oluşturmaktadır (Lim ve ark., 2016). Organik atıklar plastik, metal, kağıt vb. atıklara göre geri dönüşümü daha kolay ve katma değeri yüksek atıklardır. Genellikle organik atıkların kaynağını kentsel atıklar, tarım atıkları ve gıda endüstrisi atıkları oluşturmaktadır. Bu atıklar yakacak, hayvan yemi gibi kullanılmakta olup kompostlaştırılarak tarımda kullanılması farklı bir değerlendirme seçeneğidir.

Kompostlaştırma konusu, kompostlama prosesi ve kompost ürünü olarak iki ana alana ayrılabilir. Kompostlaştırma, organik maddenin, aerobik veya anaerobik koşullar altında çevre için daha yararlı ve uygun stabil bir yapıya biyolojik olarak ayrıştırılmasını kapsamaktadır (Epstein, 1997; Makan ve ark., 2014; Minale ve Worku, 2014). Kontrollü ve uygun şekilde yapılan kompostlama organik atığın en kaliteli geri dönüştürülmüş şeklidir. Kompost, toprak için direkt organik madde kaynağı olup, toprağın birçok özelliğine doğrudan etki etmekle birlikte bitki gelişimini teşvik etmesi ve toprak erozyonunu azaltması açısından da olumlu etkisi bulunmaktadır.

2017 y1lı verilerine göre Türkiye'de zeytin üretiminin \% 78'inin yağlık, \% 22'sinin sofralık olarak yapıldığı ve aynı yılda $1.6 \times 106$ ton yağlık zeytin üretiminin gerçekleştiği belirlenmiştir (TÜíK, 2017). Yağlık zeytin üretiminin önemli bir kısmı Marmara Bölgesi'nde yapılmaktadır. Zeytinyağı üretiminde genellikle üç yöntem (geleneksel yöntem, iki fazlı sistem, üç fazlı sistem) kullanılmakta olup seçilen üretim yöntemine göre "pirina" olarak isimlendirilen katı atık miktarlarının oranları arasında farklıklar ortaya çıkabilmektedir (İlay, 2009). Zeytinyağı üretimi için kullanılan 1 ton zeytinden, geleneksel yöntemde $400 \mathrm{~kg}$, iki fazlı sistemde $800-950 \mathrm{~kg}$ ve üç fazlı sistemlerde ise 500-600 kg pirina açığa çıkmakta olup, 2017 y1lı için $0.75-1 \times 10^{6}$ ton pirina elde edildiği tahmin edilmektedir. Zeytinyağı üretimi sırasında ve sonrasında açığa çıkan ve çoğunlukla çevre için zararlı atıklar genellikle yakacak, yem katkı maddesi ve çok küçük bir kısmı da farklı amaçlarla (tarımda organik gübre amaçlı denemelerde) (İlay ve ark., 2013) kullanılmaktadır. Üretim sistemlerine bağlı olarak farklı oranlarda ortaya çıkan yan ürünlerin miktarlarının fazla olması, bertarafinın zor olması ve depolanma sorunları nedeniyle ciddi çevresel problemlere yol açmaktadır (Azbar ve ark., 2004; Niaounakis ve Halvadakis, 2004; İlay ve ark., 2013).
Pirina, özellikle toprak karbon miktarını ve agregat stabilitesini arttırmada önemli bir kaynak olarak kullanılabilmekle beraber doğrudan toprağa uygulamanın bazı dezavantajları da olabilmektedir.

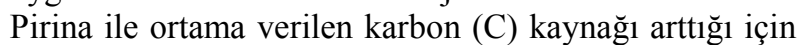
büyük miktarda azot (N) immobilizasyonu oluşabilmektedir ve bu durum bitkiler için gerekli olan $\mathrm{N}$ alımı üzerine olumsuz etki yapmaktadır. Bu nedenle pirina ile beraber uygun bir azot kaynağ 1 kullanılarak kompost yapılması önemlidir (Kavdır ve ark., 2008; İlay ve ark., 2013). Pirinanın kompostolaştırılmasında N kaynağı olarak deniz ürünleri işleme tesislerinden açığa çıkan balık atıkları kullanılabilir. Ülkemizdeki deniz ürünleri işleme tesislerinden biri de Marmara Bölgesi'nde faaliyet gösteren Dardanel Önentaş Gıda San. A.Ş.'dir. $\mathrm{Bu}$ tesiste yıllık hammadde işleme kapasitesi toplam 145800 ton $\mathrm{yl}^{-1}{ }^{-1}$ olup 2017 y1lında 37244 ton hammadde işlemiştir (Anonim 1, 2017). İşleme sonrasında kabaca \% 30-50 atık üzerinden yıllık 14900 ton katı atık ortaya çıkma potansiyeli bulunmaktadır. Balık atıkları (BA) azotça, pirina (PA) ise karbonca zengin olup her ikisi doğru oranlarda kullanılarak tarımsal kullanım için organik kompost yapılabilir. Balık atıklarının $\mathrm{C} / \mathrm{N}$ oranının küçük olmasından dolayı geniş $\mathrm{C} / \mathrm{N}$ oranı olan materyallerle karıştırılarak kompost yapımında kullanılabilir. Ayrıca BA'nın nem miktarının yüksek olmasından dolayı bu nemi adsorbe edecek materyalle karıştırılması daha yerinde olacaktır. $\mathrm{Bu}$ kriterlere en çok uyan materyallerden biri de "Pirina" dır. Pirina gibi geniş C / $\mathrm{N}$ oranlı materyallerin kendine özgü oksijen ihtiyaç kapasiteleri vardır. $\mathrm{Bu}$ atık, balık atıklarıyla karıştırıldığında amonyak gazı oluşur, amonyak ise pirinadan açığa çıkan fenol bileşiklerini nötralize eder. Aksi takdirde fenol oluşumu kompostlaştırma işleminde görev alan mikroorganizmaları engelleyerek kompostlaşmayı ve parçalanmayı yavaşlatacaktır. Organik atıkların tarımsal amaçlarla değerlendirilmesi hem çevresel hem de ekonomik açıdan önemli olup, bu atıkların en iyi değerlendirme şekli kompostlamadır. "Bu nedenle bu çalışmada PA ve BA'nın kompostlaştırılarak (BPK) toprağa uygulanması sonrasında toprağın bazı özellikleri üzerindeki etkileri araştırılmıştır.

\section{Materyal ve Yöntem}

\subsection{Kompost yapımı ve kompost analizleri}

Çanakkale ilinde bulunan Dardanel Önentaş Gıda San. A.Ş.'den balık unu şekilde BA ve Altındamla Zeytin-Zeytinyağı San. ve Tic. Ltd. Şti.'den temin edilen PA çalışmadaki kompost yapımında kullanılan ana materyallerdir. Kompost yapımında kullanılan diğer materyallerle birlikte karışım oranları ve bazı temel özellikler Çizelge 1'de verilmiştir.

Kompost materyalleri Çizelge 1'de belirtilen oranlarda karıştırıldıktan sonra kapalı sistem dönen plastik kompost kabı (kapağı havalanma için delikli) 
içinde kompostlaştırma süreci için yerleştirilmiş̧tir (şekil $1 \mathrm{a}$ ve $1 \mathrm{~b})$.

Daha sonra belirtilen miktarda su yavaş yavaş ilave edilerek nemlendirme işlemi yapılmıştır. Kompost kabı günün belirli saatlerinde güneş alacak şekilde yerleştirilmiştir. BPK yapımı 47 gün sürmüş olup süre içinde her gün kompost sıcaklığı dijital termometre ile ölçülmüsstür. Sıcaklık ölçümleri yapıldıktan sonra kompost kabı içerisindeki BPK'nın homojen olarak karışması için kompost kab1 $360^{\circ}$ döndürülmüştür. Yine bu süreçte yapılan tartıma göre eksilen su ilave edilerek nem oranı korunmuştur. Kompostlaşma sürecinde belli periyotlarda yapılan örneklemelerde $\mathrm{EC}, \mathrm{pH}$ okumaları BPK saf su $(1: 5) \mathrm{pH}$ metre ve EC metre ile yapılmıştır (TMECC, 2009).

Çizelge 1. Kompost yapımında kullanılan materyallere ait bazı özellikler ve karışım oranları

\begin{tabular}{ccccccc}
\hline Materyal & $\begin{array}{c}\mathrm{TC} \\
(\%)\end{array}$ & $\mathrm{TN}(\%)$ & $\mathrm{C} / \mathrm{N}$ & $\mathrm{pH}$ & $\begin{array}{c}\mathrm{EC} \\
\left(\mathrm{mS} \mathrm{cm}^{-1}\right)\end{array}$ & $\begin{array}{c}\text { Ağırlık } \\
(\mathrm{kg})\end{array}$ \\
\hline BA & 43.34 & 10.18 & 4.25 & 5.59 & 5.91 & 5 \\
$\mathrm{PA}$ & 49.17 & 1.25 & 39.33 & 7.46 & 3.69 & 5 \\
Talaş & 45.47 & 0.19 & 239.31 & - & - & 2.5 \\
$\mathrm{Su}$ & - & - & - & 6.80 & 0.025 & 2.5 \\
\hline
\end{tabular}

Kompost sıcaklığının sabitlendiği günden itibaren sıcaklık ölçümleri sonlandırılmış olup, yaklaşık üç ay boyunca olgunlaşmaya bırakılmıştır. Kompost örnekleri $70{ }^{\circ} \mathrm{C}$ 'de 2 gün kurutulduktan sonra bitki değirmeninde öğütülmüş ve toplam azot (TN) ve karbon (TC) içerikleri Leco TruSpec CN cihazı ile (Kirsten, 1983), nitrat ve amonyum içerikleri ise Kjeldahl buhar distilasyon cihazı kullanarak belirlenmiştir (Mulvaney, 1996).

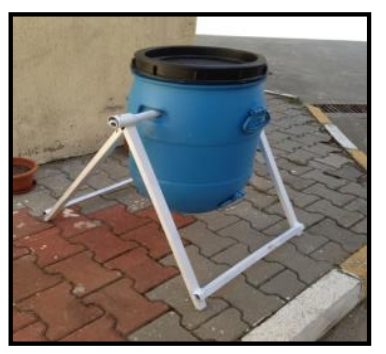

Şekil 1a. Kompost kab1 dış görünüm

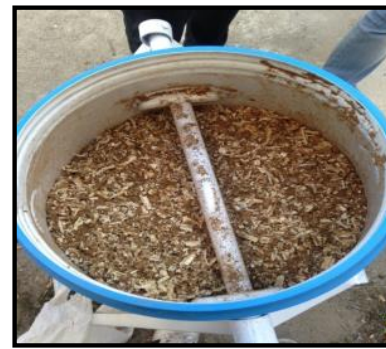

Şekil 1b. Kompost kabı iç görünüm

\section{2. İnkübasyon denemesi}

Denemede kullanılan toprak örneği $0-20 \mathrm{~cm}$ derinlikten kürek yardımı ile alınmış, laboratuvar ortamında serilip hava kuru duruma geldikten sonra 2 $\mathrm{mm}$ elek açıklığından elenmiştir. Toprak ve BPK ağırlık esasına göre \% 0 (Kontrol), \% 3, \% 6 ve \% 9 oranında olmak üzere 3 tekerrürlü olarak $1000 \mathrm{cc}$ hacminde kapaksız cam kavanozda karıştırılmıştır. Verilecek su miktarı; aynı oranlardaki karışımlar sature edildikten sonra tutabildikleri nem miktarının \% 50'si olarak belirlenmiştir. İnkübatördeki kavanozlara belirlenen oranlarda su eklenmiş ve nem seviyeleri sabit tutularak 2.5 ay boyunca $25{ }^{\circ} \mathrm{C}$ 'de bekletilmiştir. BPK ile karıştırılan toprağa ait bazı özellikler Çizelge 2'de verilmiștir.

Toprak reaksiyonu $(\mathrm{pH})$ ve elektriksel iletkenlik (EC), 1 : 2.5 (toprak : saf su) karışımında pH-metre (Grewelling ve Peech, 1960) ve EC-metre yardımıyla belirlenmiştir (Richards, 1954). Kalsiyum karbonat $\left(\mathrm{CaCO}_{3}\right)$ içeriği Scheibler kalsimetresi ile $\mathrm{CO}_{2}$ hacminin ölçülmesi esasına göre yüzde (\%) olarak hesaplanmıştır (Schlichting ve Blume, 1966). Toprak organik maddesi (OM) ise 1sitma ve kromik asit oksidasyonu ile belirlenmiştir (Smith ve Weldon, 1941). Toprak tektürü analizinden önce $\mathrm{HCl}$ ve $\mathrm{H}_{2} \mathrm{O}_{2}$ kullanılarak $\mathrm{CaCO}_{3}$ ve OM giderme işlemi yapılmıştır. Sonrasında ise toprak örneklerinde Bouyoucos (1951)'de belirtilen esaslar temel alınarak hidrometre yöntemiyle tekstür analizi yapılmıştır. Agregat stabilitesi 1-2 $\mathrm{mm}$ çaplarındaki agregat büyüklük fraksiyonundan $4 \mathrm{~g}$ tartılarak sslak eleme metoduna göre (Kemper ve Rosenau, 1986) belirlenmiştir. İnkübasyon sonundaki BPK-Toprak karışımlarının EC ve pH'sı 1 : 2.5 oranındaki karışımda belirlenmiştir (Richards, 1954).

Çalışma kapsamında elde edilen veriler SPSS 17.0 istatistik paket programında varyans analizine tabi tutulmuş, istatistiki olarak önemli bulunan $(\mathrm{p}<0.05)$ ortalama değerler çoklu karşılaştırma testiyle karşılaştırılmıştır.

Çizelge 2. Denemede kullanılan toprağa ait bazı fiziksel ve kimyasal analiz sonuçları

\begin{tabular}{cccccccc}
\hline Kum (\%) & Silt (\%) & Kil (\%) & Tekstür Sınıfi & $\mathrm{pH}$ & $\mathrm{EC}\left(\mathrm{mS} \mathrm{cm}^{-1}\right)$ & $\mathrm{CaCO}_{3}(\%)$ & $\mathrm{OM}(\%)$ \\
\hline 58.2 & 29.2 & 12.6 & Kumlu Tin & 7.66 & 0.39 & 14.42 & 1.95 \\
\hline
\end{tabular}




\section{Bulgular ve Tartışma}

\subsection{Kompostlaşma sürecine ait bulgular}

Kompost yapımının başlangıcından bitimine kadar her gün yapılan ortam ve kompost sicaklık ölçümlerine ait sıcaklık grafiği şekil 2'de verilmiştir. Buna göre kompostun başlangıç sıcaklığ $124.4{ }^{\circ} \mathrm{C}$, kompostlaşma sonundaki sıcaklığı ise $28.8{ }^{\circ} \mathrm{C}$ olarak ölçülmüsşür. Bununla birlikte ortamın başlangıç ve süreç sonundaki sıcaklığ $21.4{ }^{\circ} \mathrm{C}$ ve $27.9{ }^{\circ} \mathrm{C}$ olarak ölçülmüştür. En yüksek ve en düşük ortam sıcaklığı sirasiyla $29.8^{\circ} \mathrm{C}$ ve $12{ }^{\circ} \mathrm{C}$ olarak belirlenmiştir. 47 günlük süreçte en yüksek kompost sicaklığ 14 . günde $56.4{ }^{\circ} \mathrm{C}$ en düşük kompost sıcaklığ günde ölçülmüștür. Sicaklık ölçümleri sırasında kompost kab1 içerisindeki neme bağlı olarak mikroorganizma faaliyetlerinin yavaşladığ 1 ve bu durumun da parçalanmayı yavaşlattığı ölçümler sırasında gözlenmiştir. $\mathrm{Bu}$ dönemler şekil 2 incelendiğinde 7. ve 13. günlerde yapılan sicaklık ölçümlerinde kompost ve ortam sıcaklığının azaldığı net bir şekilde görülmektedir. Sicaklık, nem, havalanma, $\mathrm{pH}$ gibi koșulların değișmesi, çeșitli organizmaların durağan faza geçmesi veya katlanarak çoğalması ile sonuçlandığı (Insam ve De Bertoldi, 2007), bununla birlikte kompostlama materyalindeki $20{ }^{\circ} \mathrm{C}$ 'nin altındaki sıcaklıkların, kompostlama işlemini önemli ölçüde yavaşlattığı veya hatta durdurduğu bildirilmiştir (Mosher ve Anderson, 1977). Aerobik koşullarda yapılan kompostlamada mikroorganizma faaliyeti için gerekli olan oksijen ancak kompostun uygun şekillerde havalandırılmasıyla sağlanabilmektedir. Kompostlamada nem içeriği mikroorganizmaların metabolik ve fizyolojik aktivitelerini devam ettirmeleri için gerekli çözünmüş besinlerin taşınması için önemli bir çevresel değişken olup, birçok araştırmacı verimli bir kompostlama sürecinde \% 50-60 nem içeriğinin ideal olduğunu bildirmiştir (Liang ve ark., 2003).
Dolayısıyla bu çalışmada belirli zamanlarda kompost sıcaklığının düşmesinin sebebi, ortam sıcaklığının düşmesi ve buna bağlı olarak mikroorganizma faaliyetinin yavaşlaması olabilir. $\mathrm{Bu}$ zamanlarda karışımın nem oranını dengelemek için ilave edilen su ve karıştırma işleminden sonra kompost sıcaklığının yeniden yükselmesi komposttaki havalanma ve nem içeriğinin dengelenmesinin ortam sıcaklığından daha fazla etkin olduğunu ortaya koymuştur. Kompost organizmaları iki grupta (mezofil ve termofil) toplanmaktadır. Kapalı dönen sistemlerde yapılan kompost denemelerinde kompost olgunlaşma süresinin, mezofilik ve termofilik faz süresinin azaldığı (Cekmecelioglu ve ark., 2005) tespit edilmiştir. Başlangıçta $40{ }^{\circ} \mathrm{C}$ 'ye kadar mezofilik organizmalar etkili olurken, $45{ }^{\circ} \mathrm{C}$ ile $70{ }^{\circ} \mathrm{C}$ arasinda ise termofilik organizmalar başat hale geçerler (Miller, 1996). Termofilik organizmalar $35-55^{\circ} \mathrm{C}$ arasinda maksimum gelişime ulaşırken $62{ }^{\circ} \mathrm{C}$ ye kadar hızlı ayrışma devam etmekte $65{ }^{\circ} \mathrm{C}$ üzerinde ise mikroorganizmaların birçoğunun yok olduğu bildirilmiştir (Insam ve De Bertoldi, 2007). Bu nedenle bu sıcaklığın üstüne çıktığında ayrışma son derece sınırlanmakta olup, sıcaklığın düşürülmesi için kompost havalandırılması ve karıştırılması gereklidir. BPK'nın yapımında böyle bir sorunla karşılaşılmamıştır. Kompostlama başladıktan iki gün sonra mezofilik faz başlamıştır. Yapılan bu kompostta başlangıçtan dört gün sonra ise sıcaklık $50{ }^{\circ} \mathrm{C}$ 'yi geçmiştir. Yaklaşık bir ay sonra ise kompost sıcaklığı, ortam sıcaklığına ulaşmış ve bu şekilde devam etmiștir (şekil 2). Yapılan BPK'nın termofilik faz sıcaklığ $56.4{ }^{\circ} \mathrm{C}$ olarak belirlenmiş olup, uluslararası kriterlere uygun bir kompost yapımı sağlanmıștır. Termofilik fazlarda patojen, yabancı ot tohumları ve sinek larvaları öldürülmektedir, ayrıca yönetmelikler insan patojenlerinin öldürülmesi için sıcaklığın $55{ }^{\circ} \mathrm{C}$ olması gerektiğini belirtmektedirler (Rynk, 1992; Keener ve ark., 2000; Tian ve ark., 2012).

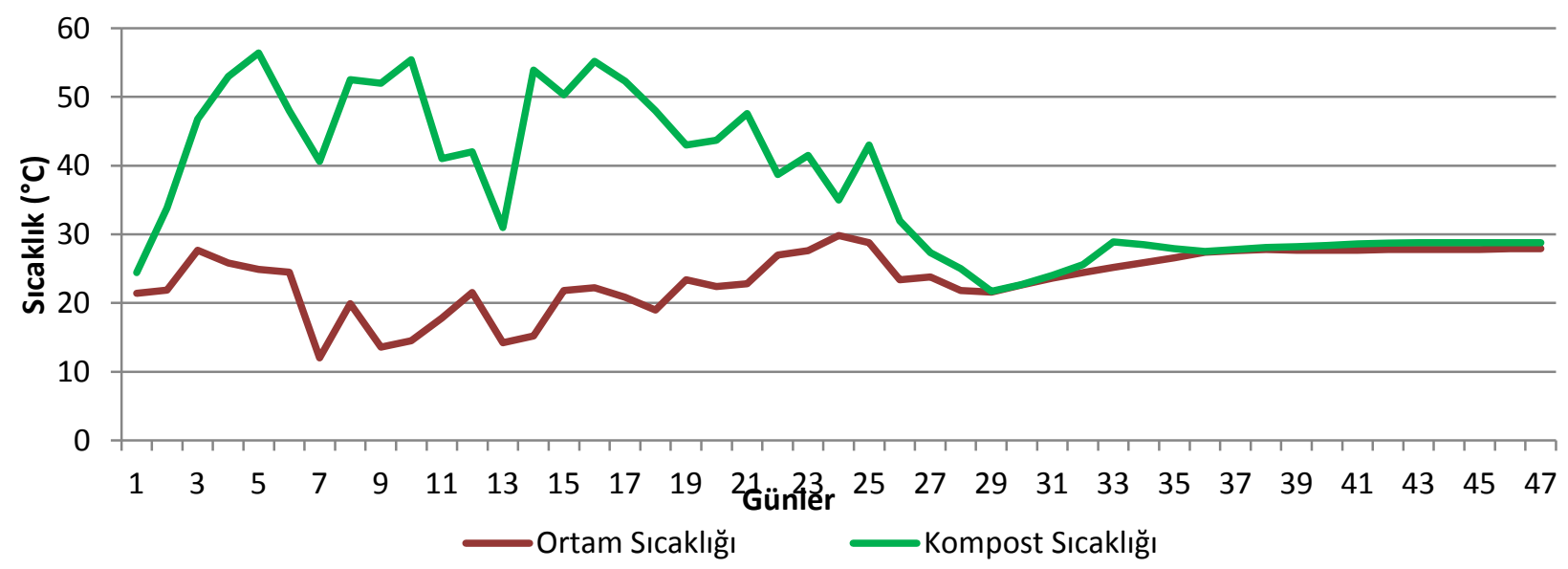

Şekil 2. Kompost - Ortam sicaklık grafiği 
Çizelge 3. BPK'ya ait bazı parametreler

\begin{tabular}{cccccccc}
\hline Materyal & $\begin{array}{c}\mathrm{TC} \\
(\%)\end{array}$ & $\begin{array}{c}\mathrm{TN} \\
(\%)\end{array}$ & $\begin{array}{c}\mathrm{NH}^{+}{ }_{4}^{-1} \\
\left(\mathrm{mg} \mathrm{kg}^{-1}\right)\end{array}$ & $\begin{array}{c}\mathrm{NO}_{3}^{-} \\
\left(\mathrm{mg} \mathrm{kg}^{-1}\right)\end{array}$ & $\mathrm{C} / \mathrm{N}$ & $\mathrm{pH}$ & $\begin{array}{c}\mathrm{EC} \\
\left(\mathrm{mS} \mathrm{cm}^{-1}\right)\end{array}$ \\
\hline Kompost & 39.93 & 2.60 & 380 & 0 & 15.31 & 8.66 & 4.79 \\
\hline
\end{tabular}

Kompostlama süreci ve sonrasındaki BPK'ya ait bazı özellikler şekil 3 ve Çizelge 3 'te verilmektedir. Kompost yapım sürecinde 4 farklı zamanda (yaklaşık 10 gün arayla) örnekleme yapılmış olup bu örneklerde kompost kalite kriterlerinden olan $\mathrm{EC}$ ve $\mathrm{pH}$ okumaları yapılmıştır. Şekil 3'ten de görüldüğü üzere her iki parametrenin de zamana bağlı olarak arttı̆g 1 tespit edilmiştir. Kompostun ilk pH değeri 8.02 ve son $\mathrm{pH}$ değeri ise 8.66 olarak belirlenmiștir. Bu iki değer karşılaştırıldığında bu süreç içinde $\mathrm{pH}$ 'nın yaklaşık $\% 8$ arttığ 1 tespit edilmiştir. İdeal bir kompostun $\mathrm{pH}$ 'sının nötre yakın değerlerde olması istenir. İyi yönetilen bir kompostlama sürecinde ayrışabilir organik maddenin yaklaşık \% 50'si $\mathrm{CO}_{2}, \mathrm{H}_{2} \mathrm{O}$, mineral tuzlara ve enerjiye dönüşmektedir (Insam ve De Bertoldi, 2007).

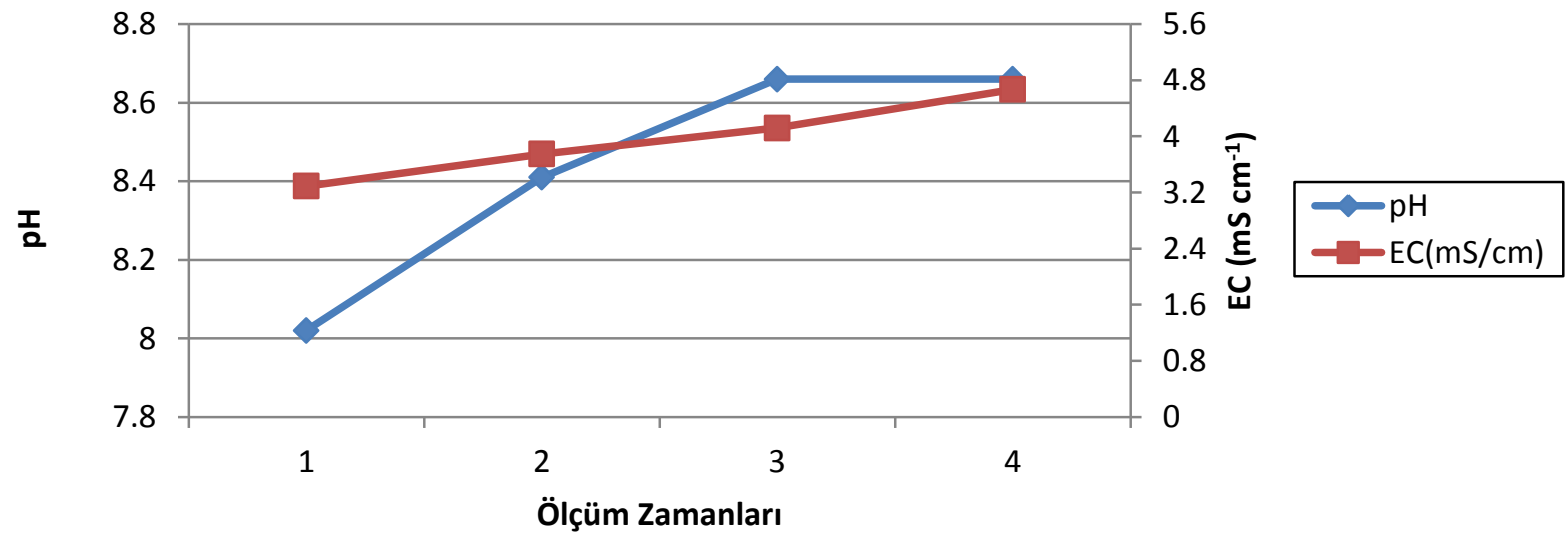

Şekil 3. Kompostlama sürecindeki EC ve pH değişimleri

Sánchez-Monedero ve ark. (2001) yaptıkları kompostlama çalışmasında ilk haftalardaki yoğun mikrobiyal aktivite ve OM ayrışması ile organik azotun önce amonyağa sonrasında ise amonyuma dönüşmesinin, $\mathrm{pH}$ 'daki artışa sebep olduğunu bildirmiştir. Zamana bağlı olarak mikrobiyal aktivitedeki artış bunun paralelinde nem, sıcaklık ve ayrışmaya bağlı ortamdaki amonyak ve bazik elementlerin artışı komposttaki pH'nın artışına neden gösterilebilir (Canet ve ark 2008). Süreçteki pH ve EC artışının nedeni, BA'daki yüksek miktardaki azotun her ne kadar kabın kapak kısmında havalandırma delikleri olsa da, yetersiz havalanmadan dolayı $\mathrm{NH}_{3}$ gazına dönüşmesi, mikrobiyal aktivite ve neme bağlı olarak çözünebilir tuz konsantrasyonunun ortamdaki artıșı olabilir. Erhart ve Burian (1997) tarafindan kompostların EC değerlerinin 0.14 ile $12.2 \mathrm{mS} \mathrm{cm}^{-1}$ arasında değiştiği bildirilmiştir. Kompostlama sürecindeki ilk EC değeri 3.29, son EC değeri 4.67 ve olgunlaşmadan sonraki değerin ise $4.79 \mathrm{mS} \mathrm{cm}^{-1}$ olduğu tespit edilmiştir. $\mathrm{Bu}$ değerlerin her ikisi de kompost toprağa karıştırılmadan, direkt bitki yetiştirme ortamı olarak kullanilacaksa, EU-Ecolabel kriterlerinin üzerindedir (Anonim 2, 2014).
BPK'nın olgunlaşmasından sonra belirlenen bazı özelliklerine ait bazı sonuçlar Çizelge 3'te sunulmuştur. Buna göre BPK'nın TC değeri \% 39.93, TN değeri \% 2.60, $\mathrm{C} / \mathrm{N}$ ise 15.31 olarak tespit edilmiştir. $\mathrm{C} / \mathrm{N}$ oranı kompost olgunlaşmasında önemli bir gösterge olup, kompostlama süreci başlangıcında 25-30 arasında olan $\mathrm{C} / \mathrm{N}$ değerlerinin olgunlaşmadan sonra 20 ve altındaki değerlerde olmasının kabul edilebilir olduğu (Hirai ve ark., 1983) bununla beraber kapalı dönen sistemlerde 10-15 arasındaki C / $\mathrm{N}$ değerlerinin de kompostlamanın tamamlanması için ideal olduğu kabul görmektedir. Kompostun C / N oranının yüksek olması, toprakta bitkiye yarayışlı azotun azalmasına neden olmaktadır (Griffin ve Hutchinson, 2007). İnorganik formdaki azotun ise genellikle $\mathrm{NH}_{4}^{+}$azotu formunda olduğu görülmektedir. Zucconi (1987) olgunlaşmış bir komposttaki maksimum $\mathrm{NH}_{4}^{+}$miktarını $400 \mathrm{mg} \mathrm{kg}^{-1}$ olması gerektiğini önermiştir. $\mathrm{BPK}$ 'nın $\mathrm{NH}_{4}^{+}$değerini $380 \mathrm{mg} \mathrm{kg}^{-1}$ olup bu literatür ile uyumludur (Çizelge 3). Bununla birlikte $\mathrm{NO}_{3}^{-}$miktarların Paredes ve ark. (2002) tarafından yapılan çalışma ile benzerlik gösterdiği ve değerlerin çok düşük olduğu tespit edilmiştir. 


\subsection{Inkübasyon denemesi ve BPK'nın toprak özellikleri üzerine etkileri}

BPK'nın yapılmasından sonra BPK'nın 2.5 aylık süreçte toprağın $\mathrm{pH}, \mathrm{EC}, \mathrm{AS}, \mathrm{TN}$ ve TC gibi özellikleri üzerine etkilerinin belirlenmesi amaciyla inkübasyon denemesi kurulmuştur. BPK kumlu tın bünyeye sahip toprak ile ağırlıkça $\% 3, \% 6, \% 9$ oranında 3 tekerrürlü olarak karıştırılmış ve belirtilen sürede inkübe edilmiştir. Şekil 4a'da BPK'nın toprak ile farklı oranlarda karıştırıldıktan ve inkübasyon yapıldıktan sonra pH'daki değişimi verilmiştir. Şekilden de görüleceği üzere artan BPK uygulamasıyla $\mathrm{pH}$ 'daki değişimin istatistiksel olarak önemli olduğu tespit edilmiştir. Bununla birlikte artan BPK dozuyla ters orantılı olarak pH'nın azaldığı; \% 9 BPK uygulamasının pH'yı, kontrol uygulamasına göre \% 5.9 azalttığı bulunmuştur.

Toprak $\mathrm{pH}$ değerinden daha yüksek $\mathrm{pH}$ değerine sahip kompost ve biyokömür uygulaması sonucunda toprağın pH değerinin düştüğü Agegnehu ve ark. (2015) tarafından da belirtilmiştir. Yine pirina uygulamasıyla topraktaki asidik fonksiyonel grupların arttığı bildirilmiştir (Brunetti ve ark., 2005). BPK'nın toprağa uygulaması sonrasında EC değişimi Şekil 4b'de sunulmuştur. Şekilden de anlaşllacağı üzere BPK uygulaması EC değerlerini aşırı şekilde arttırmıştır. Artan dozlara paralel olarak EC değerlerinin yükseldiği ve uygulamalar arasındaki farklılıkların istatistiksel açıdan önemli olduğu tespit edilmiştir. Kontrol dozunda EC $0.49 \mathrm{mS} \mathrm{cm}^{-1}$ ölçülürken, en yüksek doz olan \% 9 BPK uygulaması sonrasında EC değeri $6.75 \mathrm{mS} \mathrm{cm}^{-1}$ olarak ölçülmüş olup en yüksek BPK uygulama dozunun EC'yi kontrole göre yaklaşık 14 kat arttırdığı belirlenmiştir. Benzer şekilde pirinanın direkt olarak kullanımıyla pH'nın düştüğü, EC'nin ise arttığ 1 farklı çalışmalar yer almaktadır (Aqeel ve ark., 2007; Cucci ve ark., 2008; Kavdır ve Killi, 2008; Camposeo ve Vivaldi, 2011; Killi ve Kavdir, 2013; İlay ve ark., 2013).

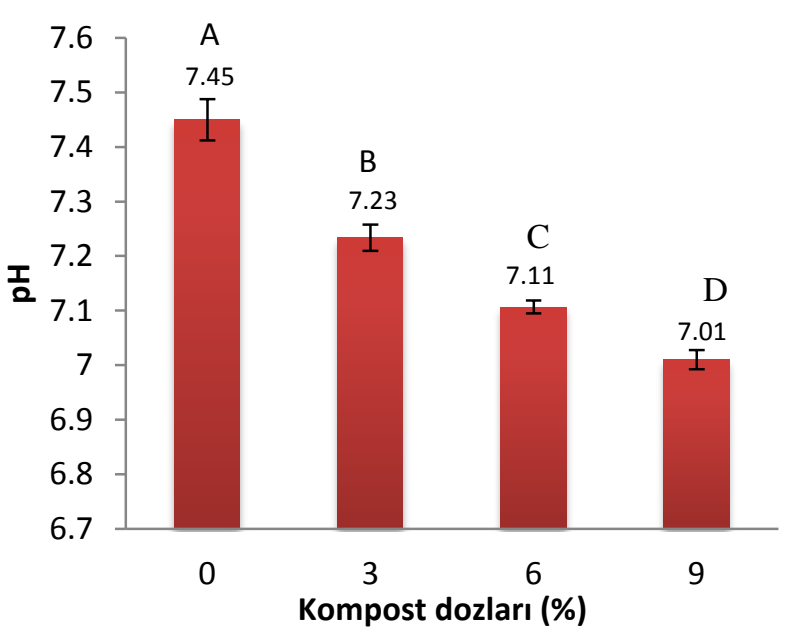

Şekil 4a. BPK uygulamasının toprak pH'sı üzerine etkisi

Toprağa BPK uygulamasının TN değerlerini istatistiki olarak önemli düzeyde arttırdığı tespit edilmiş olup BPK uygulama dozları ile toprağın TN içerikleri arasındaki ilişki Şekil 5a'da verilmiştir. Ayrıca, uygulama dozları arasındaki farklar da istatistiki açıdan önemli bulunmuştur. En yüksek TN değeri \% 9 BPK uygulamasıyla elde edilmiş olup kontrolle kıyaslandığında TN değerini \% 207 arttırdığı tespit edilmiştir. $\quad$ TC değerleri açısından da değerlendirildiğinde artan BPK dozuyla beraber toprak karbon içeriğinin de arttığı, kontrolle kıyaslandığında \% 9 BPK uygulamasının toprağın TC değerini \% 68.7 oranında arttırdığ 1 belirlenmiștir (Șekil 5b). Yine uygulamalar arasındaki TC değerleri arasındaki farkların istatistiksel olarak önemli olduğu bulunmuştur. Benzer şekilde pirinanın ham ve pirina kompostunun

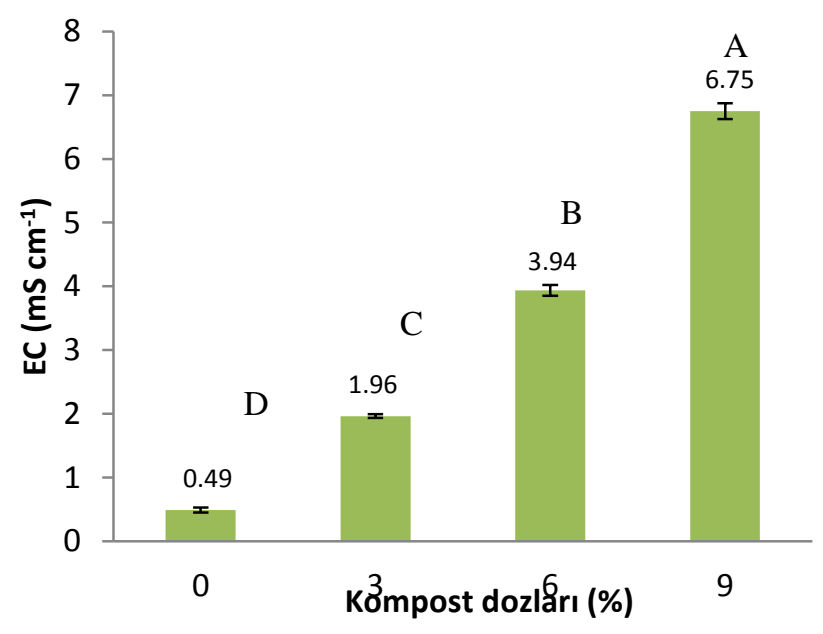

Şekil 4b. BPK uygulamasının toprak EC'si üzerine etkisi

toprağa karıştııılmasından sonra, toprak TC ve TN değerlerini

arttırdığı tespit edilmiştir (Brunetti ve ark., 2005; Kavdır ve Killi, 2008; López-Piñeiro ve ark., 2008; Kavdır ve ark., 2009; İlay ve ark., 2013).

Toprakların $\mathrm{C} / \mathrm{N}$ oranları incelendiğinde uygulanan dozun artmasına bağlı olarak $\mathrm{TN}$ içeriğindeki oransal artışın TC içeriğinin oransal artışından daha fazla olmasından dolayı $\mathrm{C} / \mathrm{N}$ oranın düştüğ $\ddot{~ g o ̈ r u ̈ l m e k t e d i r . ~}$ Kontrol uygulamasında C / N oranı 21 iken en yüksek doz uygulaması sonrasında söz konusu oranın 11.53'e düştügü belirlenmiş olup, $\mathrm{C} / \mathrm{N}$ oranının $\% 45$ azaldığ hesaplanmışırı. Ayrıca bu oranın uygulamalar arasında farklı olması istatistiki açıdan önemli bulunmuştur (şekil 6a). Killi ve Kavdır (2013), pirina ve pirina kompostu uyguladıkları toprakların $\mathrm{C} / \mathrm{N}$ değerlerinin kontrol toprağına göre önemli ölçüde azaldığını bildirmişlerdir. 
BPK uygulamasıyla toprak AS değerlerinin istatistiki olarak önemli düzeyde artı̧̧ gösterdiği tespit edilmiştir (şekil 6b). İstatistiki olarak kontrol ile \% 3 BPK uygulamasındaki AS değerleri arasında önemli bir fark olmayıp \% 6 ve \% 9 uygulamalarından farklıdır. En yüksek AS değeri \% 9 uygulamasında elde edilmiş olup $\% 9$ BPK uygulaması sonrasındaki AS değerlerinin kontrolden \% 68 daha yüksek olduğu tespit edilmiştir. Pirina ve pirina kompostu ile yapılan başka bir çalışmada pirinanın ve kompostunun toprağa uygulanmasıyla AS değerlerin arttığı tespit edilmiştir (Kavdır ve Killi, 2008; Kavdır ve ark., 2009; Killi ve Kavdır, 2013).

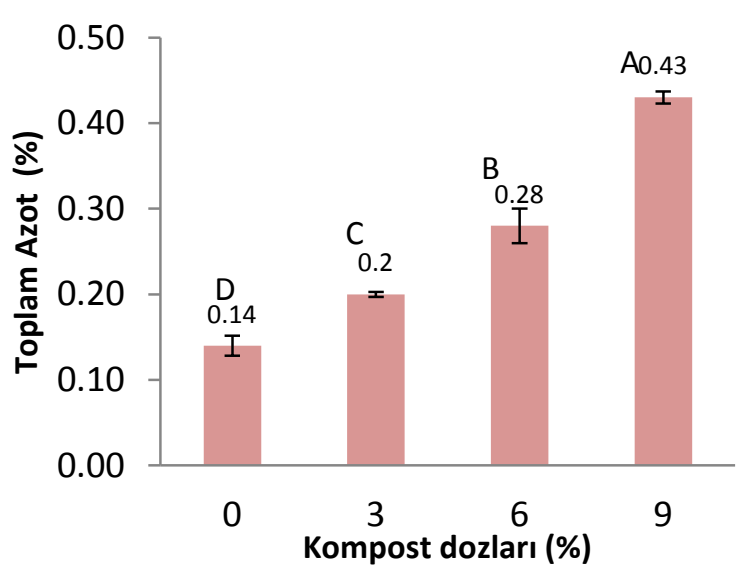

Şekil 5a. BPK uygulamasının toprak TN kapsamı üzerine etkisi

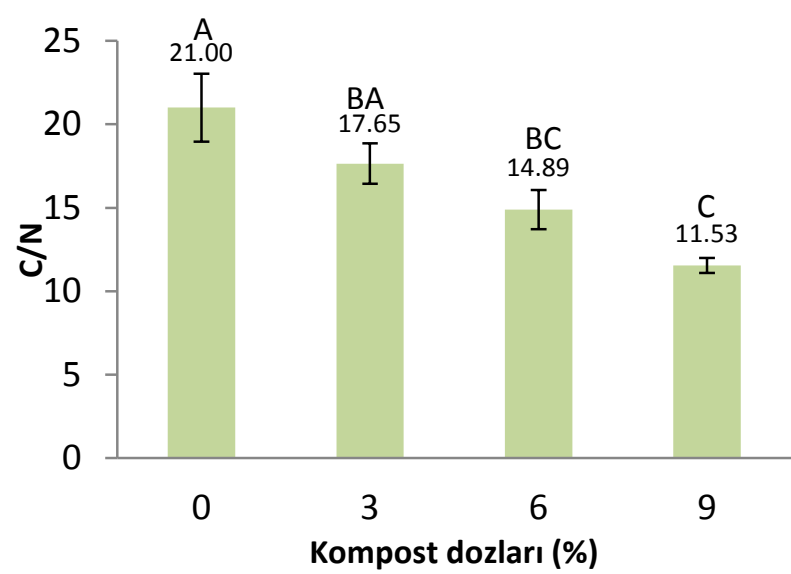

Şekil 6a. BPK uygulamasının toprak $\mathrm{C} / \mathrm{N}$ değerine etkisi

\section{Sonuç}

$\mathrm{Bu}$ çalışmada balık atıklarının $\mathrm{pH}$ değerinin asidik, pirinanın $\mathrm{pH}$ değerinin nötr civarı olması sebebi ile başta nötr $\mathrm{pH}$ değerine sahip, diğer uygun kriterlerle birlikte tarımda kullanılabilir bir kompost elde edilmesi amaçlanmıştır. Ancak ortama karıştırılan pirina, talaş ve balık atığı miktarlarının kompostlama süresince $\mathrm{pH}$ değerini nötralize edemediği, BPK'nın EC değerinin yüksek olduğu, bunun yanında $\mathrm{C} / \mathrm{N}$ değerinin ise kriterlere uygun olduğu, elde edilen verilerden anlaşılmıştır. Yine BPK'nın toprağa karıştıldıktan sonra $\mathrm{EC}$ ve $\mathrm{pH}, \mathrm{TC}, \mathrm{TN}, \mathrm{AS}$ ve $\mathrm{C} / \mathrm{N}$ değerlerini önemli

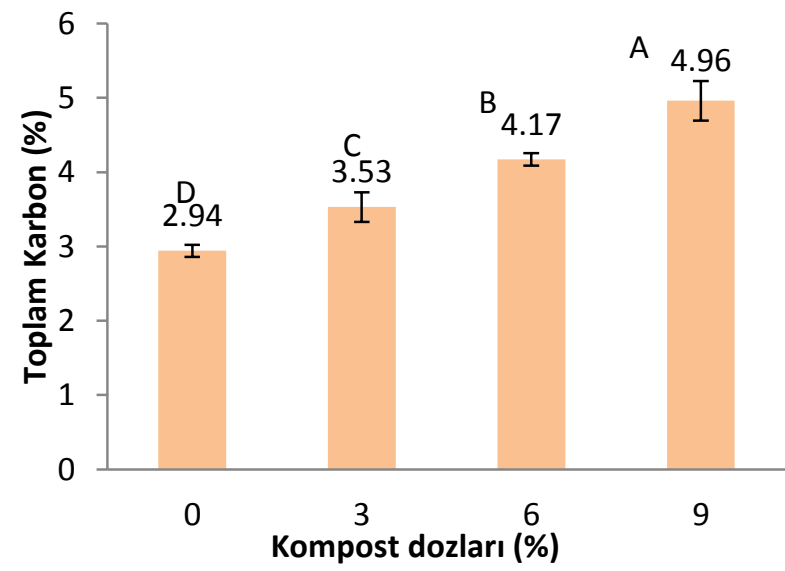

Şekil 5b. BPK uygulamasının toprak TC kapsamı üzerine etkisi

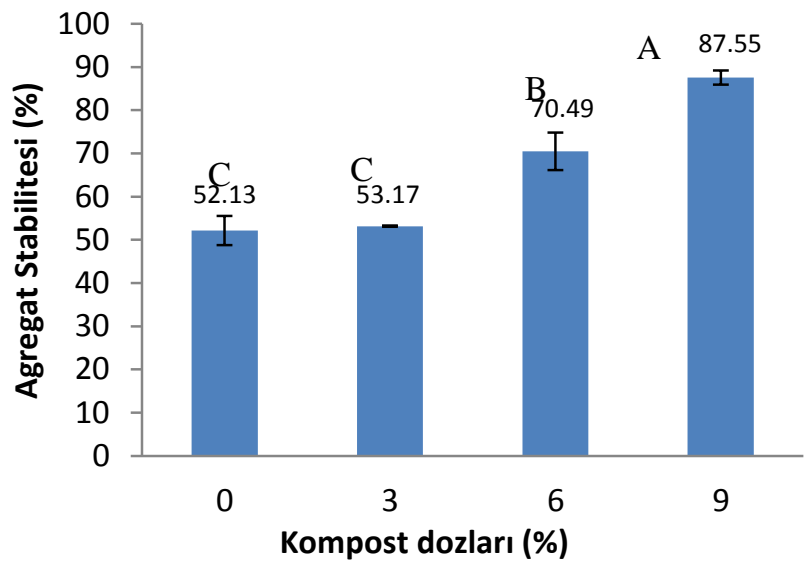

Şekil 6b. BPK uygulamasının AS üzerine etkisi

derecede değiştirdiği tespit edilmiştir ve özellikle EC'deki artışı arzu edilmeyen düzeylerde olduğu görülmektedir. Bu sebeple BPK'nın tuz içeriği yüksek olan topraklara uygulanmaması önerilmektedir. Ayrıca en yüksek kompost dozu olan \%9 uygulamasının, toprak karbonunu \% 68.7 arttırmas1 ve dolayıs1 ile toprak agregat stabilitesinin de \% 68 oranında artması nedeni ile stabilitesi düşük olan kaba tekstürlü topraklarda bu kompostun kullanılması uygun olabilir. Elektriksel iletkenlik dışındaki diğer parametreler $(\mathrm{pH}$, $\mathrm{TN}, \mathrm{TC}, \mathrm{C} / \mathrm{N}$ ve AS) dikkate alındığında \% 9 BPK uygulama dozu daha iyi sonuç verdiği bu çalışma ile ortaya konmuştur. 


\section{Teşekkür}

$\mathrm{Bu}$ çalışmada elde edilen kompost (BPK), TÜBİTAK 2241 A Sanayi Odaklı Lisans Tezi Bitirme Projesi kapsamında (2014/10, Proje başvuru no: 1139B411402234) yapılmış olup verilen desteğe teşekkür ederiz. Yine BPK yapımındaki ve çalışmadaki diğer katkılarından dolayı öğrencilerimiz Yunus Emrah KARAGÖZ, Süleyman ERKAN, Fatma Nazlı PEKER, Mert ERSAN, Yağmur BAYRAK ve Salih YETIŞSKIN'e teşekkür ederiz. Projeye destek veren ve pirinayı sağlayan Doç. Dr. Ferhan SAVRAN'a; balık atığını sağlayan Dardanel Önentaş Gıda San. A.Ş.'ye ve Gıda Mühendisi Funda ULUSOY'a teşekkürlerimizi sunarız

\section{Kaynaklar}

Agegnehu, G., Bass, A. M., Nelson, P. N., Muirhead, B., Wright, G., Bird, M.I., 2015. Biochar and biochar-compost as soil amendments: effects on peanut yield, soil properties and greenhouse gas emissions in tropical North Queensland, Australia. Agriculture, Ecosystems \& Environment, 213, 72-85. doi.org:10.1016/j.agee.2015.07.027

Anonim 1., Dardanel Ton A.Ş. 2017 yılına ait şirket faaliyet raporu. http://manage.dardanel.com.tr/Content/YatirimciIlis kileriDokuman/document-2018330135340543.pdf (Erişim Tarihi: 05 Kasım 2018).

Anonim 2., Revision of the eu ecolabel criteria for soil improvers and growing media. http://publications.jrc.ec.europa.eu/repository/bitstre am/JRC97410/si\%20gm\%20eu\%20ecolabel\%20tech nical\%20report_june2015.pdf (Erişim tarihi: 05 Kasim 2018).

Aqeel, A.M., Hameed, K.M., Alaudatt, M., 2007. Effect of olive mill by-products on mineral status, growth and productivity of Faba bean. Journal of Agronomy 6,403-408.

Azbar,

N., Bayram, A., Filibeli, A., Muezzinoglu, A., Sengul, F., Ozer, A., 2004. A review of wastes management options in olive oil production Critical Reviews on Environmental Science and

Technology, 34 (3): 209-247. doi.org:10.1080/10643380490279932.

Bouyoucos, G.J., 1951. A recalibration of the hydrometer method for making mechanical analysis, Agronomy Journal, Vol. 43, (9): 434-438. doi:10.2134/agronj1951.00021962004300090005x.

Brunetti, G., Plaza, C., Senesi, N., 2005. Olive pomace amendment in Mediterranean conditions: effect on soil and humic acid properties and wheat (Triticum turgidum L.) yield. Journal of Agricultural and Food Chemistry 53, 6730-6737.doi: 10.1021/jf050152j.

Camposeo, S., Vivaldi, G.A., 2011. Short-term effects of de-oiled olive pomace mulching application on a young super high-density olive orchard. Scientia $\begin{array}{llll}\text { Horticulturae } & 129 & \text { (4): }\end{array}$ doi.org:10.1016/j.scienta.2011.04.034.

Canet, R., Pomares, F., Cabot, B., Chaves, C., Ferrer, E., Ribó, M., Albiach, M.R., 2008. Composting olive mill pomace and other residues from rural southeastern Spain. Waste Management, 28 (12): 2585-2592. doi.org:10.1016/j.wasman.2007.11.015.

Cekmecelioglu, D., Demirci, A., Graves, R. E., Davitt, N.H., 2005. Applicability of optimised in-vessel food waste composting for windrow systems. Biosystems Engineering, 91 (4): 479-486. doi.org:10.1016/j.biosystemseng.2005.04.013.

Cucci, G., Lacolla, G., Caranfa, L., 2008. Improvement of soil properties by application of olive oil waste. Agronomy for Sustainable Development 28, 522526. doi.org:10.1051/agro:2008027.

Epstein, E., 1997. The science of composting. New York: Routledge.

Erhart, E., Burian, K., 1997. Evaluating quality and suppressiveness of Austrian biowaste composts. Compost Science \& Utilization, 5 (3): 1524. doi.org:10.1080/1065657X.1997.10701881.

Grewelling, T., Peech, M., 1960. Chemical soil test. Cornell University agr. expt. sta. bull. 960 p.

Griffin, T.S., Hutchinson, M., 2007. Compost maturity effects on nitrogen and carbon mineralization and plant growth. Compost Science \& Utilization, 15 (4): 228-236. doi.org:10.1080/1065657X.2007.10702338.

Hirai, M.F., Chamyasak, V., Kubota, H., 1983. Standard measurement for compost maturity. BioCycle: Journal of Waste Recycling, 24 (6): 54-6.

Insam, H., De Bertoldi, M., 2007. Microbiology of the composting process. In Waste management series .Vol. 8, pp. 25-48. Elsevier.

İlay, R., 2009. Zeytin katı atığının fasulye ve ayçiçeği bitkilerinin gelişimi üzerine etkilerinin saptanması. Yüksek Lisans Tezi. Çanakkale Onsekiz Mart Üniversitesi- FBE.

İlay, R., Kavdir, Y., Sümer, A., 2013. The effect of olive oil solid waste application on soil properties and growth of sunflower (Helianthus annuus L.) and bean (Phaseolus vulgaris L.). International Biodeterioration \& Biodegradation, 85: 254-259. doi.org/10.1016/j.ibiod.2013.07.008.

Kavdır, Y., İlay, R., Smucker, A.J.M., Kavdır, İ., 2009. Soil structure stabilization of olive oil solid waste and compost applied soils. International Soil Tillgage Research Organization 18th Triennial Conference, June 15th-19th 2009, İzmir, Turkey.

Kavdır, Y., Killi, D., 2008. Influence of olive oil solid waste applications on soil $\mathrm{pH}$, electrical conductivity, soil nitrogen transformations, carbon content and aggregate stability. Bioresource Technology 99, 2326-2332. doi.org:10.1016/j.biortech.2007.05.034.

Kavdir, Y., Cetin, C.S., Killi, D., İlay, R., Kavdir, I., 2008. Potential use of olive oil solid waste in 
agriculture. Journal of Adnan Menderes University, Agricultural Faculty, Special Issue: 1027-1032.

Keener, H.M., Dick, W.A., Hoitink, H.A.J., 2000. Composting and beneficial utilization of composted by-product materials. Chapter 10. pp.315-341. In: J.F. Power ve ark.(eds.). Beneficial uses of agricultural, industrial and municipal by-products. Soil Science of America. Madison, Wisconsin.

Kemper, W.D., Rosenau, R.C., 1986. Aggregate stability and size distribution. In: Methods of soil analysis. Part 1: Physical and mineralogical methods. Klute A. Ed. (Monograph no.9,2nd edn). ASA, Madison, Wis, America.

Killi, D., Kavdır, Y., 2013. Effects of olive solid waste and olive solid waste compost application on soil properties and growth of Solanum lycopersicum. International Biodeterioration \& Biodegradation, 82, $157-165$ doi.org:10.1016/j.ibiod.2013.03.004.

Kirsten, W.J., 1983. Organic elemental analysis. Academic Press, New York, NY. 1983.

Liang, C., Das, K.C., McClendon, R.W., 2003. The influence of temperature and moisture contents regimes on the aerobic microbial activity of a biosolids composting blend. Bioresource Technology, $86 \quad$ (2): 131-137. doi.org:10.1016/S0960-8524(02)00153-0.

Lim, S. L., Lee, L. H., Wu, T.Y., 2016. Sustainability of using composting and vermicomposting technologies for organic solid waste biotransformation: recent overview, greenhouse gases emissions and economic analysis. Journal of Cleaner Production, 111: 262-278 doi.org:10.1016/j.jclepro.2015.08.083.

López-Piñeiro, A., Albarrán, A., Rato Nunes, J.M., Barreto, C., 2008. Short and medium-term effects of two-phase olive mill waste application on olive grove production and soil properties under semiarid mediterranean conditions. Bioresource Technology 99, 7982-7987. doi.org:10.1016/j.biortech.2008.03.051.

Makan, A., Assobhei, O., Mountadar, M., 2014. Initial air pressure influence on in-vessel composting for the biodegradable fraction of municipal solid waste in Morocco Int. J. Environ. Sci. Technol., 11: pp. 53-58. doi.org:10.1007/s13762-013-0434-6.

Miller, F.C., 1996. Composting of municipal solid waste and its

components. A.C Palmisano, M.A Barlaz (Eds.), Microbiology of Solid Waste, CRC Press, Boca Raton, pp. 115-154.

Minale, M., Worku, T., 2014. Anaerobic co-digestion of sanitary wastewater and kitchen solid waste for biogas and fertilizer production under ambient temperature: waste generated from condominium house Int. J. Environ. Sci. Technol., 11: 509-516. doi.org:10.1007/s13762-013-0255-7.

Mosher, D., Anderson, R.K., 1977. Composting sewage sludge by high-rate suction aeration techniques - the process as conducted at Bangor, ME, and some guidelines of general applicability. Interim Report Number SW-614d. US Government Printing Office, Washington, DC.

Mulvaney, R.L., 1996. Nitrogen-inorganic forms. p. 1123-1184. In D.L. Sparks et al. (ed.) Methods of soil analysis. Part 3. 3rd ed. SSSA Book Ser. 5. ASA and SSSA, Madison, WI.

Niaounakis, M., Halvadakis, C.P., 2004. Olive-mill waste management: literature review and patent survey 960-402-123-0, Typothito-George Dardanos Publications, Athens.

Paredes, C., Bernal, M. P., Cegarra, J., Roig, A., 2002. Bio-degradation of olive mill wastewater sludge by its co-composting with agricultural wastes. Bioresource Technology, 85 (1): 1-8. doi.org/10.1016/S0960-8524(02)00078-0.

Richards L.A., 1954. Diagnosis and Improvement of Saline and Alkali Soils. U.S. Department of Agriculture Handbook No: 60. 94 p.

Rynk, R., 1992. On farm composting handbook. NRAES-54, Cooperative Extension Service, Northeast Regional Agricultural Engineering Services, Ithaca, NY, USA.

Sánchez-Monedero, M.A., Roig, A., Paredes, C., Bernal, M.P., 2001. Nitrogen transformation during organic waste composting by the Rutgers system and its effects on $\mathrm{pH}, \mathrm{EC}$ and maturity of the composting mixtures. Bioresource Technology, 78 (3): 301-308. doi.org/10.1016/S0960-8524(01)00031-1.

Schlichting E., Blume E., 1966. Bodenkundliches Practikum. Verlag Paul Parey, Hamburg und Berlin.

Smith, H. W., Weldon, M. D., 1941. "A comparison of some methods for the determination of soil organic matter." Soil Science Society of America Journal 5.C : 177-182.

Tian, Y., $\quad$ Chen, L., Gao, L., Michael Jr., F.C., Keener, H.M., Klingman, M., Dick, W.A., 2012. Composting of waste paint sludge containing melamine resin and the compost's effect on vegetable growth and soil water quality J. Hazard. Mater, 243:

pp. 28-36. doi.org:10.1016/j.jhazmat.2012.09.013.

TMECC., 2009. Test Methods for the examination of composting and compost (4.10. Electrical conductivity for compost; 4.11. Electrometric $\mathrm{pH}$ determinations for compost). US Composting Council.

TÜİK., 2017. Türkiye İstatistik Kurumu. http://www.tuik.gov.tr/PreIstatistikTablo.do?istab_ id=1073 (Erişim tarihi: 25.10.2018)

Zucconi, F., 1987. Compost specifications for the production and characterization of compost from municipal solid waste. Compost : production, quality and use. Elsevier Applied Science, pp 3050. 